\title{
Original Article PATTERNS OF CONGENITAL HEART DISEASE AMONG PATIENTS ATTENDING IN SPECIALIZED HOSPITALS
}

\author{
Fatema Rahman', Md. Nazmul Hassan Refat ${ }^{2}$, Md. Saydur Rahman ${ }^{3}$
}

\begin{abstract}
Background: Incidence of congenital heart disease is serious and common conditions that have significant impact on morbidity, mortality and healthcare costs in children and adults. The objective of this paper is socio-demographic characteristics, pattern, risk factors and geographical distribution of Congenital Heart Disease (CHD).

Methods: This cross-sectional study was conducted throughout the year of 2013 in Dhaka city of Bangladesh. Among the children with confirmed diagnosis of CHD within the age ranging from birth to 18 years, admitted and treated at National Institute of Cardiovascular Disease (NICVD) and National Heart Foundation and Research Center (NHFRC) were included.
\end{abstract}

Result: Out of 168 patients, 64\% were living in rural area, 36\% were living in urban. The study revealed that 58.9\% of male were predominant whereas female was $41.1 \%$. The mean $( \pm \mathrm{SD})$ age of patients was $4.87( \pm 2.83)$ years. $71.4 \%$ of the children were within 1 to 5 years of age. $36.9 \% \mathrm{CHD}$ was diagnosed at the age of $1-5$ years. Finding of the study revealed that there were different types of CHD namely Ventricular Septal Defect (VSD) $35.15 \%$, Atrial Septal Defect (ASD) 27.4\%, Patent Ductus Arteriosus (PDA) 13.7\%, Coarctation of the aorta 4.8\% and Tetralogy of Fallots $19 \%$. In urban area, 37.4\% patients had VSD while in rural area, 31.1\% patients had ASD. This variation of CHD in relation to living place of the patients was statistically important $\left(\chi^{2}{ }_{4}=11.62, \mathrm{p}=0.024\right)$. In female patients, VSD is more than 58\%, however in male patients, ASD is more than 36.4\%. This variation of CHD according to sex of the patients was statistically vital $\left(\chi^{2}{ }_{4}=27.85, \mathrm{p}=0.001\right)$. Among the mothers, $39.8 \%$ utilized Ant-natal Care (ANC) had VSD while $24.0 \%$ having VSD did not utilized ANC. This variation was statistically significant $\left(\chi^{2}=8.235, p=0.04\right)$. Among the patients, $41.7 \%$ were aged 1-5 years who had VSD while 50.0\% were aged 6-10 years who had ASD. This variation was statistically important as it showed $\left(\chi^{2}{ }_{8}=43.601, \mathrm{p}=0.000\right)$.

Conclusions: As the most common type of congenital heart diseases are VSD and ASD, the findings of this study will contribute in early detection and proper management of CHD in the contexts to others and thus save lives.

JOPSOM 2020; 39(2): 40-44

https://doi.org/10.3329/jopsom.v39i2.53164

Keywords: Pattern; Congenital Heart Disease; VSD; ASD; PDA.

1. Lecturer, Department of Community Medicine, Holy Family Red Crescent Medical College Hospital, Dhaka.

2. Medical Officer, Department of Public Health and Hospital Administration, NIPSOM, Mohakhali, Dhaka

3. Colonel and Additional Director Administration, DNCC Dedicated Corona Hospital, Mohakhali, Dhaka

Correspondence: Dr. Fatema Rahman. E-mail: rahmanfatema@ gmail.com

\section{INTRODUCTION}

The heart develops as a single tube which folds back on itself and then divides into two separate circulations during fetal development. Congenital heart disease (CHD) is the commonest of all congenital lesions accounting for nearly $28 \%$ of all congenital malformations and is the most common type of heart disease among children. Most cases are asymptomatic and discovered during routine neonatal checkup. ${ }^{1}$ Nearly one third of the CHD are critical requiring intervention in the first year of life. ${ }^{2}$ It is believed sixty percent of all infants suffering from congenital heart disease often fail to enjoy their first birthday. The incidence of congenital heart disease is approximately 8 per 1000 live birth and this incidence has remained constant worldwide. ${ }^{3}$ The proportion of this disease prevalence is the same as incidence across the globe. ${ }^{4}$ A recent systemic review reported that the highest prevalence 9.3/1000 live births in Asia due to high birth rate and consanguineous marriages and the lowest prevalence 8.2/1000 live births in Africa. ${ }^{5}$ In Bangladesh, a birth prevalence of CHD is 8.3 per 1000 
live recently. ${ }^{6}$ Only $2-5 \%$ the children are getting some form of treatment and the rest remain undetected and untreated with the result that most of them die. Now with modern cardiac surgery, more than $85 \%$ of the estimated 25,000 infants born annually with CHD are likely to reach adulthood ${ }^{7}$ If the problems are recognized at earlier age by frequent antenatal checkup and screening of apparently healthy children for $\mathrm{CHD}$, the chance of long term complications are less and the outcome is better. As a result of improved medical and surgical management, more children with CHD are surviving into adolescence and adulthood. ${ }^{8}$ According to recent update report of the American Heart Association, atrial septal defect (ASD), ventricular septal defect (VSD), tetralogy of fallot (TOF), patent ductus arteriosus (PDA), pulmonary stenosis, aortic stenosis, coarctation of aorta, and atrioventricular septal defect accounts for $85 \%$ of all CHDs. ${ }^{9}$

\section{METHODS}

It was a cross sectional study to determine the pattern of congenital heart disease among the patients attending in specialized hospitals. The total period of the study was from January to December 2013.The study was carried out in two specialized hospital in Dhaka city i.e. National Institute of Cardiovascular
Diseases (NICVD) and National Heart Foundation and Research Center (NHFRC). Children from birth to 18 years of age who had congenital heart disease confirmed by echocardiography were included. Patients with other than CHD and seriously ill or sick patient were excluded. But considering the constraints, 168 congenital heart disease patients were included in the study. So sample size of the study was 168. Data were collected by semi-structured questionnaire and cheek list by face-to-face interview and review of medical records of patients respectively. All data were analyzed by using the "Statistical Package for Social Sciences (SPSS)" software. For descriptive statistics mean and standard deviations for numerical data and frequencies \& proportions for categorical data was calculated as required.

\section{RESULTS}

Total 168 children were diagnosed with CHD during the study period. The study revealed $58.9 \%$ were male and the rest $41.1 \%$ were female, male and female ratio was $1.43: 1$. Majority of the patients were diagnosed 1-5 years of age and among them major respondents were illiterate. Majority of the patients $64 \%$ were living in rural areas (Table 1).

Table 1: Socio demographic profile of patients $(n=168)$

\begin{tabular}{|c|c|}
\hline Variables & $\mathbf{n}(\%)$ \\
\hline Age group & $120(71.4)$ \\
\hline $1-5$ & $38(22.6)$ \\
\hline $6-10$ & $10(6)$ \\
\hline $11-14$ & \\
\hline Sex & $99(58.9)$ \\
\hline Male & $69(41.1)$ \\
\hline Female & $107(64)$ \\
\hline Residence & $61(36)$ \\
\hline Rural & $63(37.5)$ \\
\hline Urban & \\
\hline Education: (Illiterate) & $41(24)$ \\
\hline Housing condition & $55(33)$ \\
\hline Pucca & $72(43)$ \\
\hline Semi-pucca & \\
\hline Kacha & \\
\hline
\end{tabular}


Majority i.e. $40(58 \%)$ female had VSD while it was $19(19.2 \%)$ in male. On the other hand, majority i.e.
$36(36.4 \%)$ male had ASD while it was $10(14.5 \%)$ in female.

Table 2: Distribution of the patient by gender and type of CHD

\begin{tabular}{|c|c|c|c|c|c|c|}
\hline \multirow[b]{2}{*}{ Sex } & \multicolumn{6}{|c|}{ Type of CHD } \\
\hline & $\begin{array}{l}\text { VSD } \\
\mathbf{f}(\%)\end{array}$ & $\begin{array}{l}\text { ASD } \\
\mathbf{f}(\%)\end{array}$ & $\begin{array}{l}\text { PDA } \\
\text { f (\%) }\end{array}$ & $\begin{array}{l}\text { Coarctation of } \\
\text { the aorta } f(\%)\end{array}$ & $\begin{array}{l}\text { Tetralogy of } \\
\text { Fallots f }(\%)\end{array}$ & $\begin{array}{l}\text { Total } \\
\mathbf{f}(\%)\end{array}$ \\
\hline Male & $19(19.2)$ & $36(36.4)$ & $16(16.2)$ & $05(5.1)$ & $23(23.2)$ & $99(100.0)$ \\
\hline Female & $40(58.0)$ & $10(14.5)$ & $07(10.1)$ & $03(4.3)$ & $09(13.0)$ & $69(100.0)$ \\
\hline Total & $59(35.1)$ & $46(27.4)$ & $23(13.7)$ & $08(4.8)$ & $32(19.0)$ & $168(100.0)$ \\
\hline Significance & \multicolumn{6}{|c|}{$\chi_{(4)}^{2}=27.85, p=0.001$} \\
\hline
\end{tabular}

Majority i.e. (41.7\%) of the patients were within 15 year age had VSD while $(50 \%)$ of ASD patients were within 6-10 years age group and most of patients $(80 \%)$ are within $11-14$ years age.

Table 3: Association between distribution of the patients by age group and type of CHD

\begin{tabular}{|c|c|c|c|c|c|c|}
\hline \multirow{2}{*}{$\begin{array}{l}\text { Age group } \\
\text { (Years) }\end{array}$} & \multicolumn{6}{|c|}{ Type of CHD } \\
\hline & VSD & ASD & PDA & $\begin{array}{c}\text { Coarctation of } \\
\text { the aorta }\end{array}$ & $\begin{array}{c}\text { Tetralogy of } \\
\text { Fallots }\end{array}$ & Total \\
\hline \multirow{2}{*}{$1-5$} & 50 & 19 & 23 & 8 & 20 & 120 \\
\hline & $41.7 \%$ & $15.8 \%$ & $19.2 \%$ & $6.7 \%$ & $16.7 \%$ & $100.0 \%$ \\
\hline \multirow{2}{*}{$6-10$} & 8 & 19 & 0 & 0 & 11 & 38 \\
\hline & $21.1 \%$ & $50.0 \%$ & $0.0 \%$ & $0.0 \%$ & $28.9 \%$ & $100.0 \%$ \\
\hline \multirow{2}{*}{$11-14$} & 1 & 8 & 0 & 0 & 1 & 10 \\
\hline & $10.0 \%$ & $80.0 \%$ & $0.0 \%$ & $0.0 \%$ & $10.0 \%$ & $100.0 \%$ \\
\hline \multirow{2}{*}{ Total } & 59 & 46 & 23 & 8 & 32 & 168 \\
\hline & $35.1 \%$ & $27.4 \%$ & $13.7 \%$ & $4.8 \%$ & $19.0 \%$ & $100.0 \%$ \\
\hline Significance & \multicolumn{6}{|c|}{$\chi_{(8)}^{2}=43.601, p=0.000$} \\
\hline
\end{tabular}

Among all mothers of the patients, majority 47(39.8\%) utilized ant-natal care (ANC) had VSD while 19(38\%) utilized ant-natal care (ANC) had ASD (table 3). 
Table 4: Association between the ant-natal care (ANC) utilization and type of CHD

\begin{tabular}{|c|c|c|c|c|c|c|}
\hline \multirow{2}{*}{$\begin{array}{c}\text { Ante-natal care } \\
\text { (ANC) utilized }\end{array}$} & \multicolumn{6}{|c|}{ Type of CHD } \\
\cline { 2 - 7 } & VSD & ASD & PDA & $\begin{array}{c}\text { Coarctation of } \\
\text { the aorta }\end{array}$ & $\begin{array}{c}\text { Tetralogy of } \\
\text { Fallots }\end{array}$ & Total \\
\hline \multirow{2}{*}{ Yes } & 47 & 27 & 15 & 4 & 25 & 118 \\
\cline { 2 - 7 } & $39.8 \%$ & $22.9 \%$ & $12.7 \%$ & $3.4 \%$ & $21.2 \%$ & $100.0 \%$ \\
\hline \multirow{2}{*}{ No } & 12 & 19 & 8 & 4 & 7 & 50 \\
\cline { 2 - 7 } & $24.0 \%$ & $38.0 \%$ & $16.0 \%$ & $8.0 \%$ & $14.0 \%$ & $100.0 \%$ \\
\hline \multirow{2}{*}{ Total } & 59 & 46 & 23 & 8 & 32 & 168 \\
\cline { 2 - 7 } & $35.1 \%$ & $27.4 \%$ & $13.7 \%$ & $4.8 \%$ & $19.0 \%$ & $100.0 \%$ \\
\hline \multirow{2}{*}{ Significance } & & \multicolumn{7}{|c|}{$\chi_{(4)}^{2}=8.235, \mathrm{p}=0.04$} & \\
\hline
\end{tabular}

By residing place, majority i.e. (37.4\%) of patients residing in urban area had VSD while it was (31.1\%) in rural area. On the other hand, majority i.e. (25.2\%) of patients residing in urban area had ASD while it was $(31.1 \%)$ in rural area. (table- 4$)$.

Table- 5: Association between type of CHD and residing place of the patients

\begin{tabular}{|c|c|c|c|c|c|c|}
\hline \multirow{2}{*}{ Residing place } & \multicolumn{7}{|c|}{ Type of CHD } \\
\cline { 2 - 7 } & $\begin{array}{c}\text { VSD } \\
\mathbf{f}(\%)\end{array}$ & $\begin{array}{c}\text { ASD } \\
\mathbf{f}(\%)\end{array}$ & $\begin{array}{c}\text { PDA } \\
\mathbf{f}(\%)\end{array}$ & $\begin{array}{c}\text { Coarctation of } \\
\text { the aorta f (\%) }\end{array}$ & $\begin{array}{c}\text { Tetralogy of } \\
\text { Fallots f (\%) }\end{array}$ & $\begin{array}{c}\text { Total } \\
\mathbf{f}(\%)\end{array}$ \\
\hline Urban & $40(37.4)$ & $27(25.2)$ & $16(15.0)$ & $01(0.9)$ & $23(21.5)$ & $107(100.0)$ \\
\hline Rural & $19(31.1)$ & $19(31.1)$ & $07(11.5)$ & $07(11.5)$ & $09(14.8)$ & $61(100.0)$ \\
\hline Total & $59(35.1)$ & $46(27.4)$ & $23(13.7)$ & $08(4.8)$ & $32(19.0)$ & $168(100.0)$ \\
\hline Significance & \multicolumn{7}{|c|}{$\chi_{(4)}^{2}=11.62, \mathrm{p}=0.024$} \\
\hline
\end{tabular}

\section{DISCUSSION}

The most common congenital malformation is the congenital heart disease. The study shows that most encounter congenital pathologies were ventricular septal defect which is more in female than male. Majority of the patients were diagnosed 1-5 years of age and among them major respondents were illiterate. Majority of the patients $64 \%$ were living in rural area. In our country rural people have lack of knowledge about health problem and less diagnostic (Echo) facilities. Out of 168 mothers, (70.2\%) utilized ante natal care, $(29.8 \%)$ did not utilize ant-natal care during their pregnancy which could be due to social customs, unavailability of ANC services and lack of awareness.
In this study, majority of the patients i.e. (71.4\%) were within 1 to 5 years, $(22.6 \%)$ were within 6 to 10 years and rest $(6 \%)$ were within 11 to 14 years. Mean $( \pm S D)$ age of patient was $4.87( \pm 2.83)$ years. Mollah at el found that most of the children are presented by 1 years of age. But in this study, most are presented within 1-5 years of age because most cases are asymptomatic and discovered during routine medical checkup. ${ }^{10}$

The study revealed that majority 62(36.9\%) CHD was diagnosed at age 1 to 5 years, $31 \%$ was within 1 month to 1 year and $17.9 \%$ was within 1 month and $14.3 \%$ was diagnosed after 5 years of age. Hussain et al. during early nineties found only $8.3 \% \mathrm{CHD}$ at neonatal period. ${ }^{11}$ Manzoor et al. found 44.99\% CHD were diagnosed during neonatal period. ${ }^{12}$ CHD is 
underestimated due to home deliveries and early discharge of mothers along with their neonate from hospitals without proper neonatal examination.

In this study, out of 168 children, 59(35.15\%) were found to have VSD, 46(27.4\%) were found to have ASD, 23(13.7) were found to have PDA, 8(4.8\%) were found to have Coarctation of the aorta, 32(19\%) were found to have Tetralogy of Fallots. In another study. Sadiq et al. found the incidence of VSD was $32 \%$ of all CHD in patients presenting to a tertiary care. ${ }^{\mathbf{1 3}}$ VSD was found the commonest CHD. Manzoor et al in Bangladesh found VSD $27.48 \%$ as the commonest CHD. ${ }^{12}$ But Rahman et al found ASD $39.88 \%$ as commonest CHD. ${ }^{14}$ Fatema et al found ASD $36.78 \%$ as the commonest CHD in neonate. ${ }^{15}$ This difference in observation might due to that Rahman et al and Fatema et.al. included many adult patients in their study. A significant proportion of VSD close spontaneously before adulthood and some untreated patients with large VSD die in childhood from heart failure. On the other hand, ASD patients may remain asymptomatic in childhood and are diagnosed for the first time when they are adult. ${ }^{8}$

\section{CONCLUSION}

Most cases are asymptomatic and discovered during routine medical checkup. Therefore, we recommend that all murmur should be screened unless thought to be physiological. So early detection of CHD is possible by 2D and proper counseling of the parents will help in early intervention and reduce mortality and morbidity of children. This study might help to make people aware, thereby help policy makers take decision concerning early case detection, treatment and prevention of CHD.

\section{REFERENCES}

1. Islam MN, Hossain MA, Khaleque MA, Das MK, Khan MRH, Bari MS, Bhuiyan MKJ. Prevalence of Congenital Heart Disease in Neonate in a Tertiary Level Hospital. Nepal Journal of Medical sciences. 2013; (2):91-95.

2. Lawn JE, Cousens S, Zupan J. Lancet Neonatal Survival Steering Team. 4 million neonatal deaths: When? Where? Why? Lancet; 2005; 365:891-900.

3. Razzaq AY, Bener, L. A study of possible deleterious effects of consanguinity. Clin Genet. 1997; 51:167-173.

4. Lorenzo D, Adolfo C. Decreasing the burden of congenital heart anomalies: an epidemiologic evaluation of risk factors and survival of Congenital Heart Diseases. Progress in Pediatric Cardiology. 2003; 18:111-121.

5. van der Linde D, Konings EE, Slager MA, Witsenburg M, Helbing WA, Takkenberg JJ, et al. Birth prevalence of congenital heart disease. Worldwide: A systematic review and meta-analysis. J Am Coll Cardiol. 2011:58: 2241-7.

6. Razzaque Sk, Nahar S, Akhter S, Jahan N, Begum J. National Institute of Cardiovascular Diseases, congenital rubella, congenital heart disease and its prevention in the developing country like Bangladesh. Bangladesh heart journal. 2007; 22:34.

7. Shermin LS, Hoque MA, Iqbal M, Ayub M. Pattern and clinical profile of congenital heart disease in a teaching hospital, TAJ. 2008; 21:5862.

8. Roger VL, GO AS, Lloyd-Jones DM, Benjamin EJ, Berry JD, Borden WB et al. Heart disease and stroke statistics - 2012 update a report from the American Heart Association. 25: e2-e220. Available from: http://circ.ahajournals.org. [Accessed on 11 Apr 2018].

9. Mollah MAH, Begum NA, Islam MN, Mahmud RS, Haq MA, Nahar N, Rashid MA. Clinical Profile of Congenital Heart Diseases (CHD): An Analysis of 218 Cases. Bangladesh heart J. 2002; 17:62-67.

10. Hussain M, Amin SK, Moller MR. Pattern of Congenital Heart Disease in Dhaka Shishu Hospital. D S (Child) H J. 1992; 8:35-46.

11. Hussain M, Tahura S, Sayeed M, Rahman M, Rahman M, Kar S. Past and Present Pattern of Congenital Heart Disease at Dhaka Shishu Hospital: A Situation Analysis. Bangladesh Journal of Child Health. 2012; 34(2):51-55.

12. Sadiq M, Roshan B, Latif F, Bashir I, Sheikh SA, Khan A. Patternof paediatric heart disease in Pakistan. J Col Physicians Surg Pak 2002; 12:149-53.

13. Rahman S, Ahmed MN, Rahmatullah KHI, Alam MS. The Incidence of Congenital Heart Diseases Diagnosed Non-Invasive Technique Ten Years Study in Bangladesh. DS (Child) HJ. 1992; 8:5-15.

14. Fatema NN, Chowdhury RB, Chowdhury L. Prevalence of congenital heart disease among hospital live birth in a tertiary hospital of Bangladesh. CVJ. 2008; 1:14-20. 